\title{
BMJ Open General practitioners' perspectives on the prevention of cardiovascular disease: systematic review and thematic synthesis of qualitative studies
}

\author{
Irene Ju, ${ }^{1,2}$ Emily Banks, ${ }^{3,4}$ Bianca Calabria, ${ }^{3,5}$ Angela Ju, ${ }^{1,2}$ Jason Agostino, ${ }^{6}$ \\ Rosemary J Korda, ${ }^{3}$ Tim Usherwood, ${ }^{7}$ Karine Manera, ${ }^{1,2}$ Camilla S Hanson, ${ }^{1,2}$ \\ Jonathan C Craig, ${ }^{1,2}$ Allison Tong ${ }^{1,2}$
}

To cite: Ju I, Banks E, Calabria B, et al. General practitioners' perspectives on the prevention of cardiovascular disease: systematic review and thematic synthesis of qualitative studies. BMJ Open 2018;8:e21137. doi:10.1136/ bmjopen-2017-021137

- Prepublication history and additional material for this paper are available online. To view these files, please visit the journal online (http://dx.doi org/10.1136/bmjopen-2017021137).

Received 3 January 2018 Revised 27 September 2018 Accepted 3 October 2018

Check for updates

(C) Author(s) (or their employer(s)) 2018. Re-use permitted under CC BY-NC. No commercial re-use. See rights and permissions. Published by BMJ.

For numbered affiliations see end of article.

Correspondence to

Ms Irene Ju;

euju2374@uni.sydney.edu.au

\section{ABSTRACT}

Objective Cardiovascular disease (CVD) is a leading cause of morbidity and mortality globally, and prevention of CVD is a public health priority. This paper aims to describe the perspectives of general practitioners (GPS) on the prevention of CVD across different contexts.

Design Systematic review and thematic synthesis of qualitative studies using the Enhancing Transparency of Reporting the Synthesis of Qualitative research (ENTREQ) framework.

Data sources MEDLINE, Embase, PsycINFO and CINAHL from database inception to April 2018.

Eligibility criteria for selecting studies We included qualitative studies on the perspectives of GPs on CVD prevention.

\section{Data extraction and synthesis We used}

HyperRESEARCH to code the primary papers and identified themes.

Results We selected 34 studies involving 1223 participants across nine countries. We identified six themes: defining own primary role (duty to prescribe medication, refraining from risking patients' lives, mediating between patients and specialists, delegating responsibility to patients, providing holistic care); trusting external expertise (depending on credible evidence and opinion, entrusting care to other health professionals, integrating into patient context); motivating behavioural change for prevention (highlighting tangible improvements, negotiating patient acceptance, enabling autonomy and empowerment, harnessing the power of fear, disappointment with futility of advice); recognising and accepting patient capacities (ascertaining patient's drive for lifestyle change, conceding to ingrained habits, prioritising urgent comorbidities, tailoring to patient environment and literacy); avoiding overmedicalisation (averting long-term dependence on medications, preventing a false sense of security, minimising stress of sickness) and minimising economic burdens (avoiding unjustified costs to patients, delivering practice within budget, alleviating healthcare expenses).

Conclusions GPs sought to empower patients to prevent CVD, but consideration of patients' individual factors was challenging. Community-based strategies for assessing CVD risk involving other health professionals, and decision aids that address the individuality of the patient's health
Strengths and limitations of this study

- Qualitative studies conducted in range of settings and populations were synthesised to generate a more comprehensive understanding of decision-making and approaches to cardiovascular disease prevention among general practitioners.

- Some studies did not specify whether an absolute risk assessment or individual risk factor approach was used, and differences between perspectives on primary and secondary prevention were unclear.

- Non-English articles were excluded, which may limit the transferability of the study's findings.

and environment, may support GPs in their decisions regarding CVD prevention.

\section{INTRODUCTION}

Cardiovascular disease (CVD) is the leading cause of global morbidity and mortality, contributing to over $30 \%$ of deaths worldwide. $^{1-3}$ Cardiovascular events are highly preventable, through population and individual-level interventions such as smoking cessation, weight reduction, physical activity and exercise, and blood pressure and lipid lowering therapies. ${ }^{4}$

High-quality primary care is critical to CVD prevention, ${ }^{56}$ due to the opportunity to assess risks and to provide lifestyle and pharmacological interventions. It is widely recommended that primary prevention of CVD be based on the assessment and management of absolute risk, ${ }^{78}$ but there is evidence of research practice gaps, with inconsistencies in the use of risk assessment tools and guidelines,${ }^{8-10}$ advice on lifestyle interventions and prescription of preventive medications. ${ }^{11} 12$

While these shortfalls are likely to be due to many factors ${ }^{5}{ }^{13}$ including challenges in 
managing diverse patient populations and variability in patient motivation, ${ }^{14}$ more detailed data on why this occurs at the healthcare provider level are limited, hindering practical strategies for improvement. General practitioners (GPs) play a key role in assessment and management of CVD risk and qualitative studies have elucidated their perspectives on primary and secondary prevention of CVD. A synthesis of qualitative studies can generate a more comprehensive understanding of the reasons for decisions and approaches to CVD prevention across different settings and populations in primary care. We aimed to describe the spectrum of GP perspectives to inform strategies that may address concerns, uncertainties and the challenges in CVD prevention, to support decisions and implementation of evidence-based strategies for the prevention of CVD and improved healthcare outcomes.

\section{METHODS}

The reporting of this study follows the Enhancing Transparency of Reporting the Synthesis of Qualitative research (ENTREQ) framework ${ }^{15}$ and the PRISMA (Preferred Reporting Items for Systematic Reviews and Meta-Analyses) checklist $^{16}$ (online supplementary file 1 ).

\section{Selection criteria}

Qualitative studies on the perspectives of GPs regarding the primary and secondary prevention of CVD were eligible for inclusion. GPs were defined as physicians who assumed responsibility for providing 'continuing and comprehensive medical care to individuals, families and communities, ${ }^{17}$ and included primary care physicians and family practitioners. Studies published in peer-reviewed journals and doctoral dissertations were included. We excluded quantitative surveys, epidemiological studies (eg, randomised trials), non-primary research articles (eg, reviews), clinical guidelines, economic studies and non-English articles to minimise misinterpretation in translation.

\section{Data sources and searches}

We used a sensitive search strategy, which is provided in online supplementary file 2. Searches were conducted in MEDLINE, Embase, PsycINFO and CINAHL from database inception to 15 April 2018. We searched the ProQuest Dissertation and Thesis database, British Library Electronic Digital Thesis Online Service and the Europe E-theses Portal for doctoral dissertations. Primary care journals, Google Scholar and reference lists of included studies were also searched. Titles and abstracts were screened by IJ who excluded studies that did not meet the inclusion criteria. The full texts of the remaining articles were assessed for eligibility.

\section{Assessment of study reporting}

To evaluate comprehensiveness and transparency of reporting in each study, we used the COREQ
(Consolidated Criteria for Reporting Qualitative Health Research). The framework included reporting items specific to the research team, study methods, context of the study, analysis and interpretations. Three reviewers (IJ, AJ and $\mathrm{CSH}$ ) independently assessed each study, and any inconsistencies were resolved by discussion.

\section{Synthesis}

Using thematic synthesis, ${ }^{18}$ we entered all the participant quotations and text from the 'Results' section of each paper into the software HyperRESEARCH (version 3.0.3; ResearchWare, Randolph, Massachusetts, USA) to code the data. Author IJ read each article line-by-line and coded text into inductively derived concepts that reflected GPs' perspectives on the prevention of CVD. Author IJ translated concepts within and across studies by interpreting the data from the primary studies and coded text to existing concepts (that had been identified in previous studies), or by creating a new concept (that was not identified in previous studies) when necessary. Similar concepts were grouped into themes. The preliminary themes were discussed with the research team (AJ, AT) who also read the included studies. This form of investigator triangulation ensures that the full range and depth of data reported in the original studies are captured in the analysis. We identified conceptual links and developed a thematic schema. We cross-tabulated the themes with primary and secondary prevention strategies for CVD (eg, medications, lifestyle or behavioural change, risk assessment tools and service delivery models).

\section{Patients and public involvement}

Patients were not directly involved in this systematic review of GPs' perspectives on prevention of CVD.

\section{RESULTS}

\section{Literature search}

Of the 7405 articles identified in the search, we included 34 studies, involving more than 1223 GPs (one study did not report the number of participants, figure 1). The characteristics of the studies are provided in table 1. Across the studies, interviews, focus groups and questionnaires with open-ended questions were used to collect the data.

\section{Comprehensiveness of reporting in included studies}

The comprehensiveness of reporting varied, with studies addressing 6 to 19 of the 24 criteria for reporting of qualitative studies (table 2). The participant selection strategy and the participant characteristics were reported in all $34(100 \%)$ studies. The duration and the venue of data collection was specified in $20(59 \%)$ and $10(29 \%)$ studies, respectively. Twenty-eight (82\%) studies reported researcher triangulation, and $17(50 \%)$ studies reported on their use of software to facilitate data analysis. Quotations were provided in $30(88 \%)$ studies.

\section{Synthesis}

We identified six themes: defining own primary role; trusting external expertise; motivating behavioural 

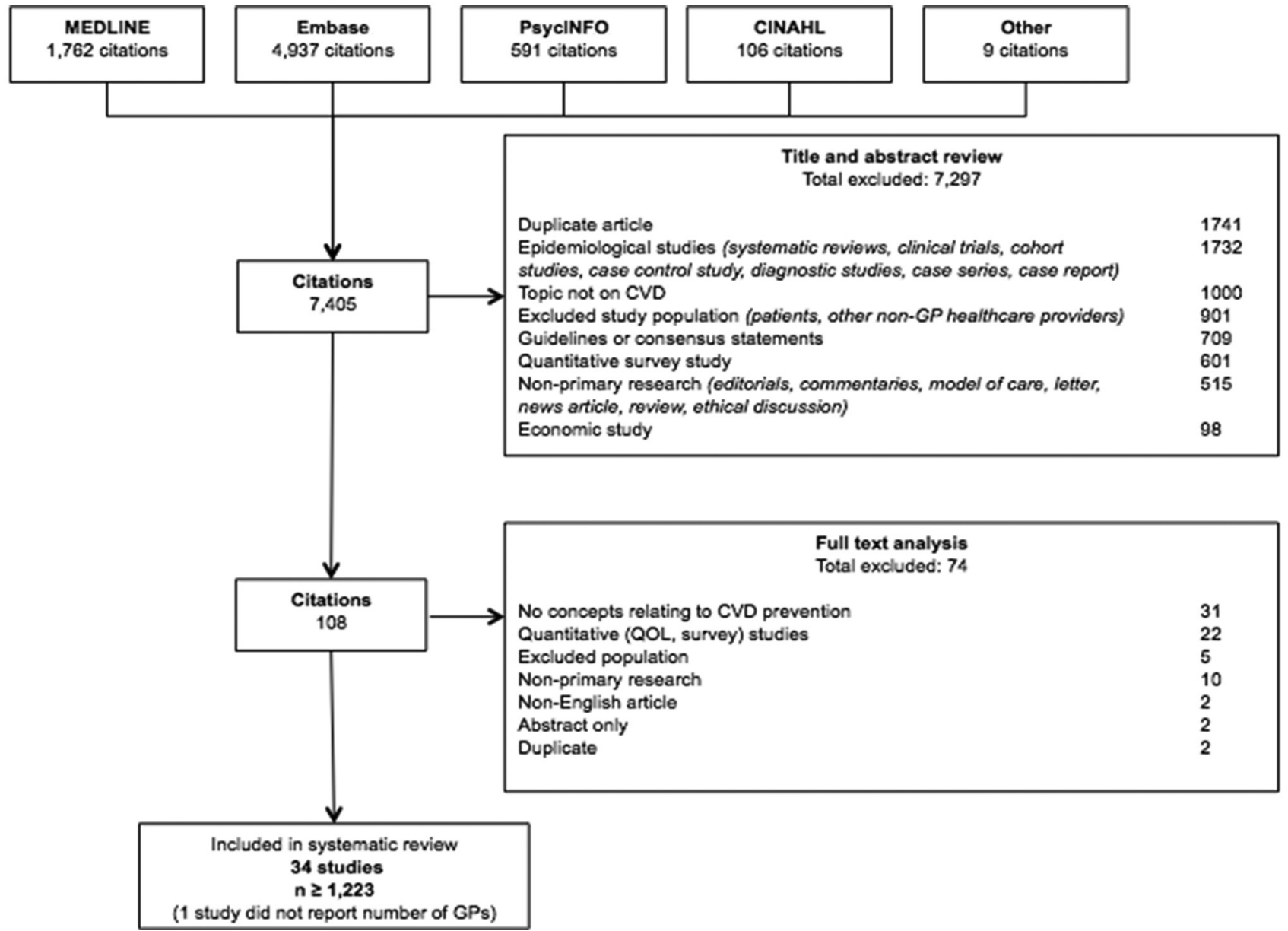

Figure 1 Search results. CVD, cardiovascular disease; GP, general practitioner; QOL, quality of life.

change for prevention; recognising and accepting patient capacities; avoiding medicalisation and minimising economic burdens. Selected quotations for each theme are provided in table 3 . The relationships among themes are shown in figure 2. Figure 3 shows a matrix of the themes that related to each CVD prevention strategy. Most studies did not specify if perspectives related to primary or secondary prevention or a specific population (eg, high risk); however where possible, these have been delineated in the synthesis.

\section{Defining own primary role}

Duty to prescribe medication

Some GPs believed their core role, as a physician, was to "offer the tablets" ${ }^{19}$ and prescribe medicines, whereas counselling patients to make lifestyle changes was a secondary focus. Preventive medication was perceived by some as being less imposing than lifestyle changes, as it would not impede on patients' 'quality of life'. ${ }^{20}$

\section{Refraining from risking patients' lives}

Some GPs were highly cautious and wary of putting patients' lives at risk such that they exercised absolute 'vigilance'21 and advised patients to take preventive medications regardless of their risk of CVD. This was seen as more effective in preventing CVD-related death compared with recommendations for lifestyle change'[GPs] would always recommend preventative medication to their patients,... "I don't take the slightest risk with someone else's life". ${ }^{22}$

\section{Partnering with specialists}

As patients at high risk of CVD often had comorbidities, some GPs 'co-managed'21 their patients with specialists. 'Working together', with specialists meant reinforcing, to the patient, the specialist's advice and GPs believed that this would strengthen cohesive care for the patient.

\section{Delegating responsibility to patients}

Some GPs defined their role as an 'influencer ${ }^{23}$ in their patients' self-motivation and management. They could only provide information but believed it was ultimately the patients' duty to make lifestyle changes or take their medication. Enforcing medications and behavioural change on patients was deemed unethical and not within their professional purview, and seen as 'presumptuous to make such strong demands'. ${ }^{20}$

\section{Providing holistic care}

Some GPs emphasised their desire to take on a generalist role by providing comprehensive care and being 


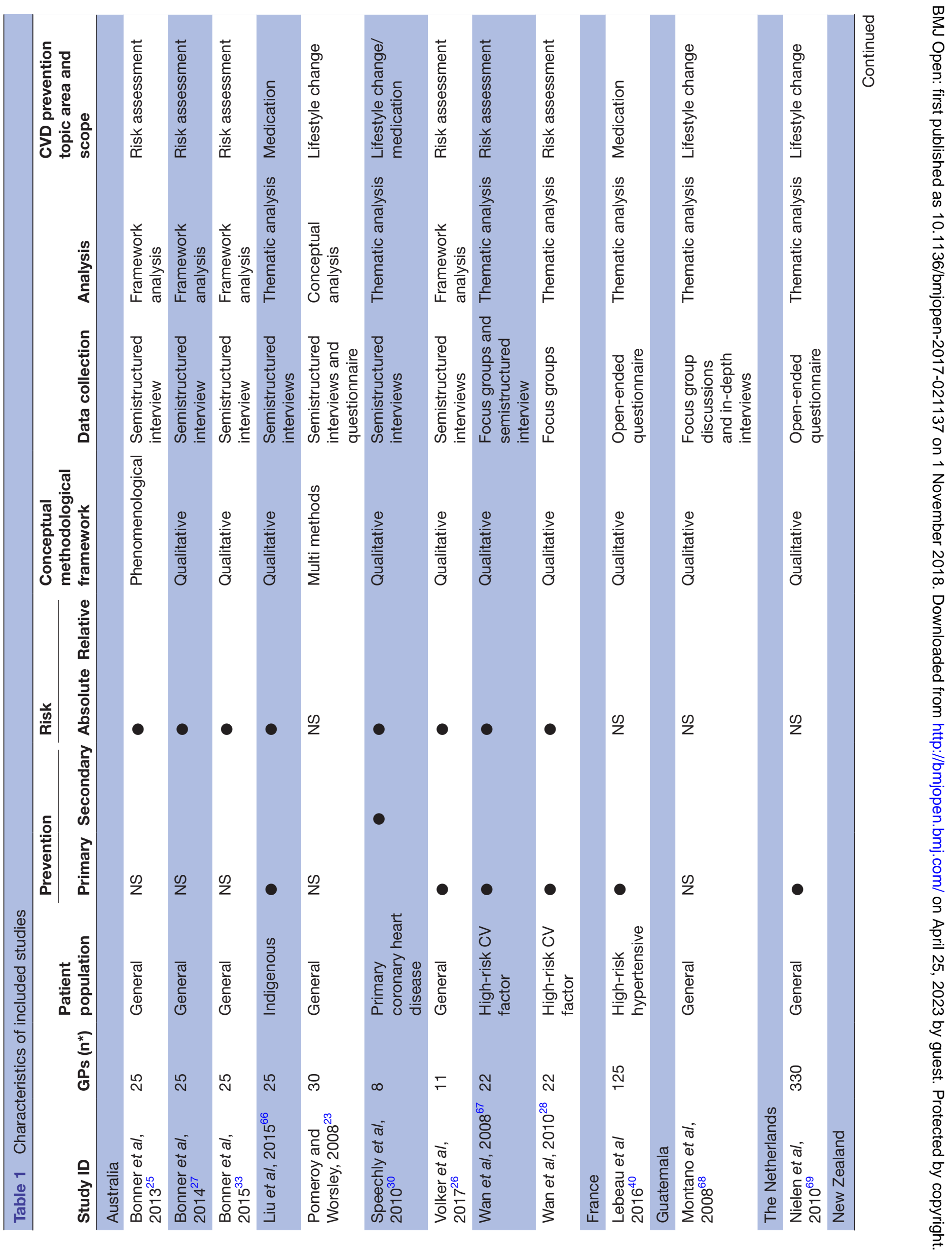




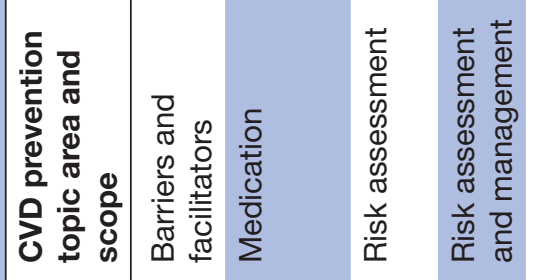

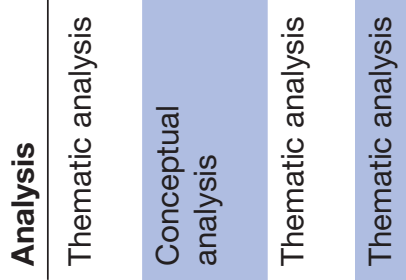

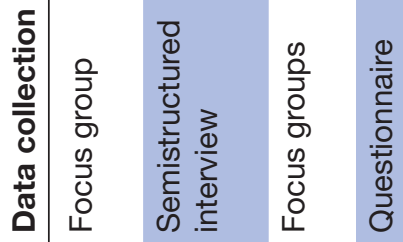

可

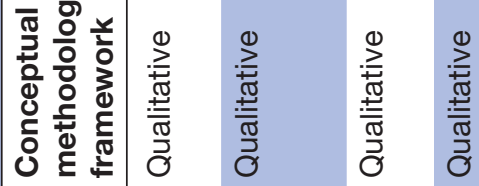

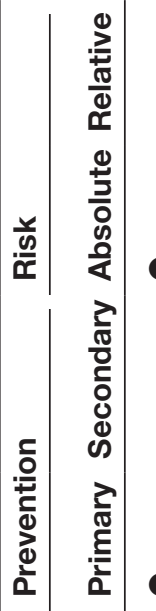

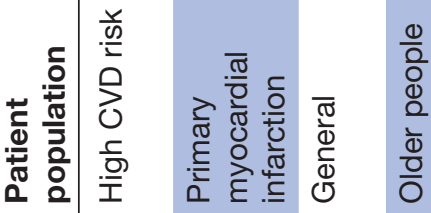

\section{ริ}

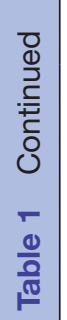
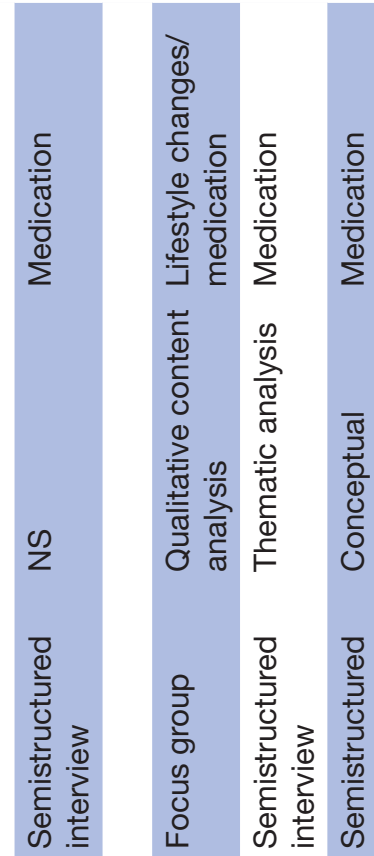

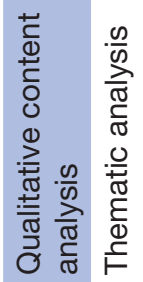

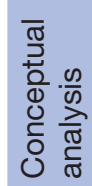
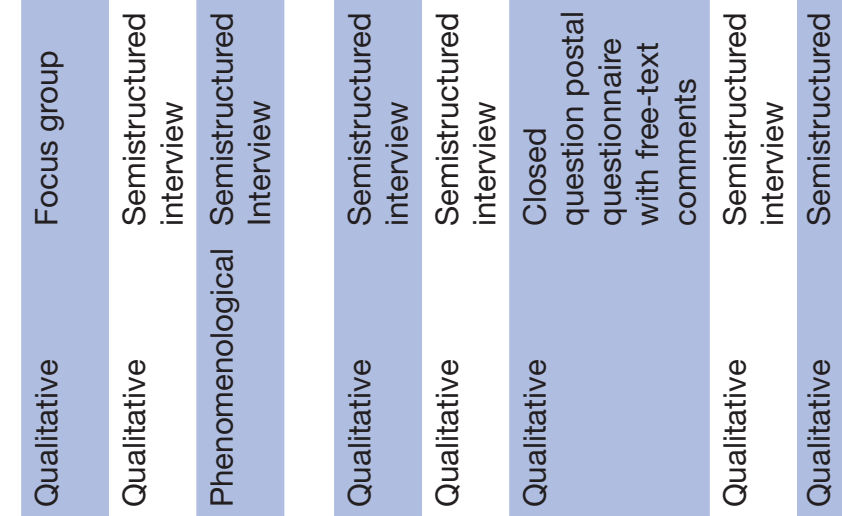

$\frac{9}{2}$

$\stackrel{n}{z}$
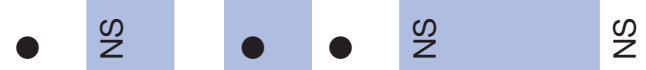

里
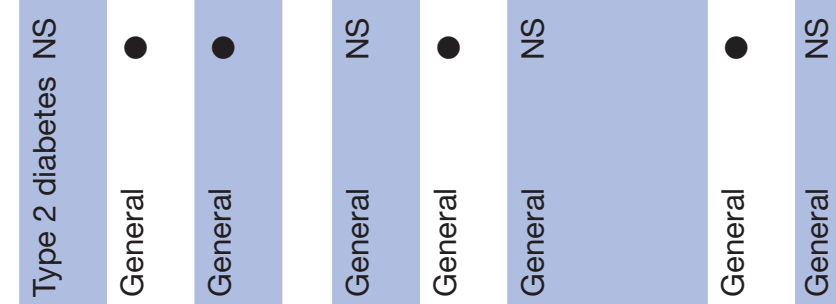

त্ত

$\frac{1}{0}$
$\frac{1}{1}$
$\frac{1}{0}$

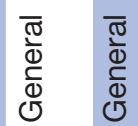

ก $\frac{\text { ก }}{2}$

아

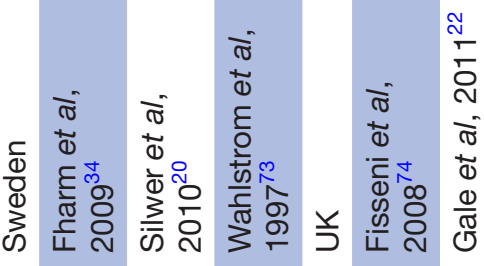

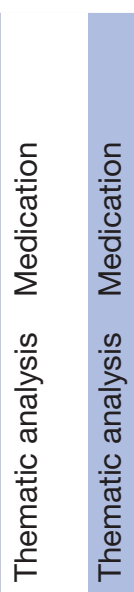

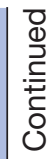

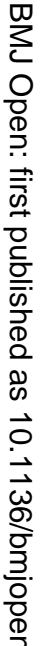

$\stackrel{\sqrt[N]{*}}{a}$

$\stackrel{\text { ON }}{\vec{\omega}}$

인

$\vec{z}$

券

$\stackrel{N}{\circ}$

ర్

흥

잉

$\overrightarrow{\mathrm{O}}$

镸

产.

$\stackrel{10}{3}$

产.

○

9

을.

N

芯

פ

응

뭉

$\stackrel{\mathbb{1}}{\stackrel{1}{1}}$

뭉

을 


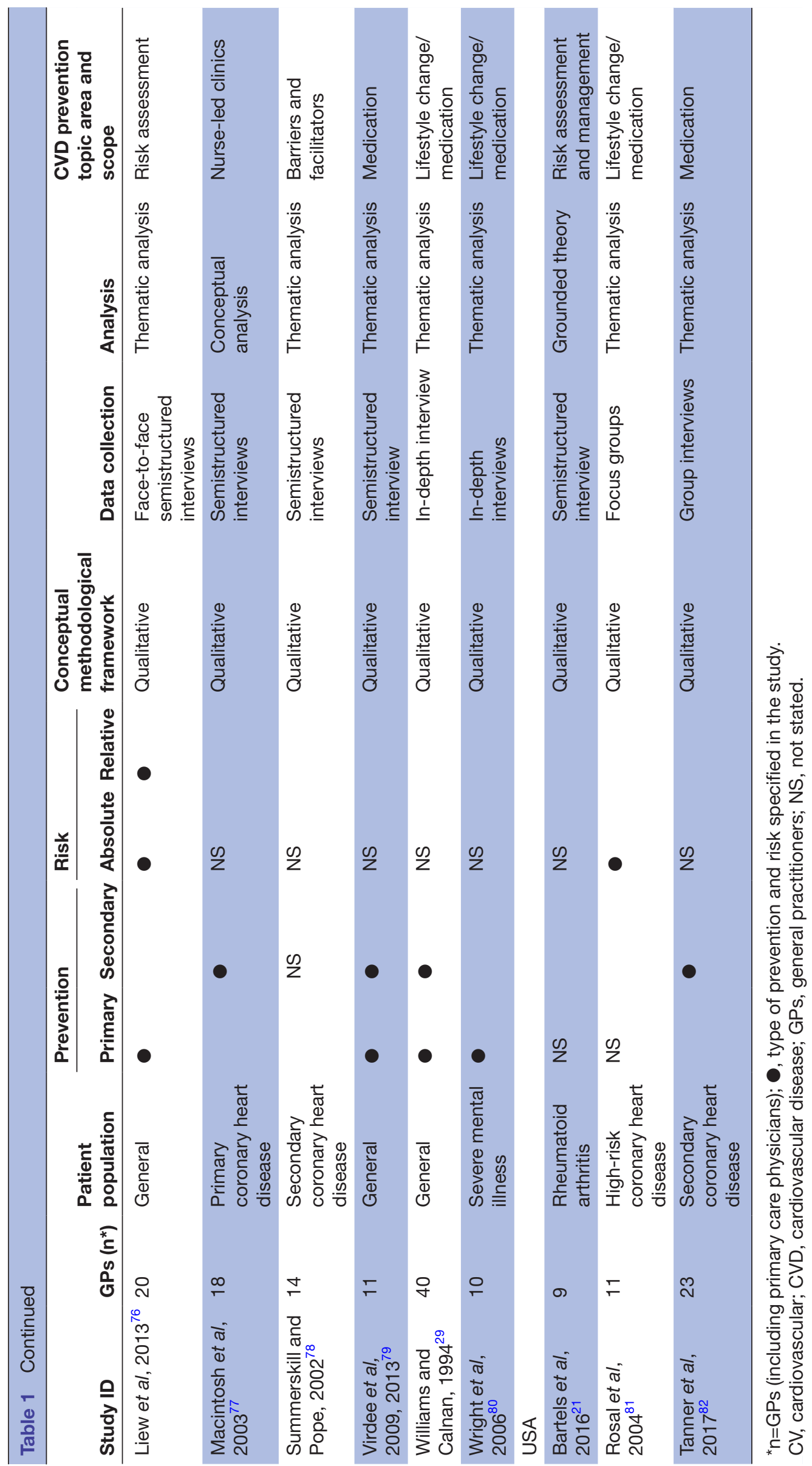


Table 2 Completeness of reporting in the included studies

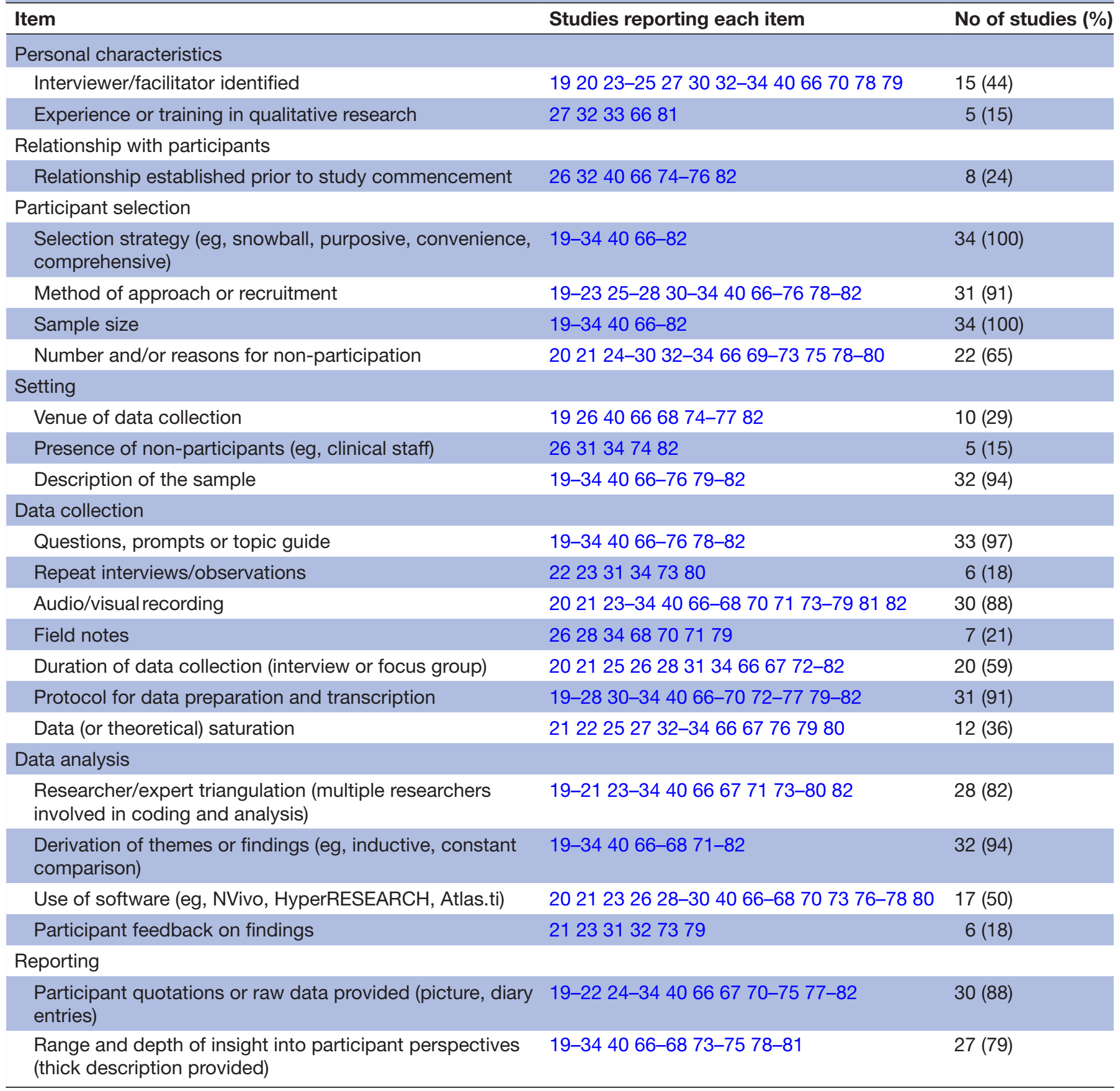

'carers for the total patient,' which included taking responsibility for lifestyle, nutrition education and prescribing medicine. Some GPs considered that this also involved 'creating a positive expectation', ${ }^{20}$ enabling the patient to feel optimistic about the preventive strategy outcomes, which was important for patient motivation.

\section{Trusting external expertise}

Depending on credible evidence and opinion

Some GPs trusted research evidence and expert opinion to feel secure about their decisions. Guidelines, risk assessment tools and 'editorials in the (British Medical Journal) $\mathrm{BMJ}{ }^{24}$ were seen to minimise room for human error and were more reliable than their own judgement-'I'm comfortable to be guided by the experts rather than try and invent too much on what might be dodgy assumptions on my part., ${ }^{25}$

Entrusting care to other health professionals

Educating patients about diet and nutrition to prevent CVD was regarded by some as being 'outside their interest and expertise ${ }^{, 23}$ and believed that dieticians or other clinicians were better able to inform patients about lifestyle 


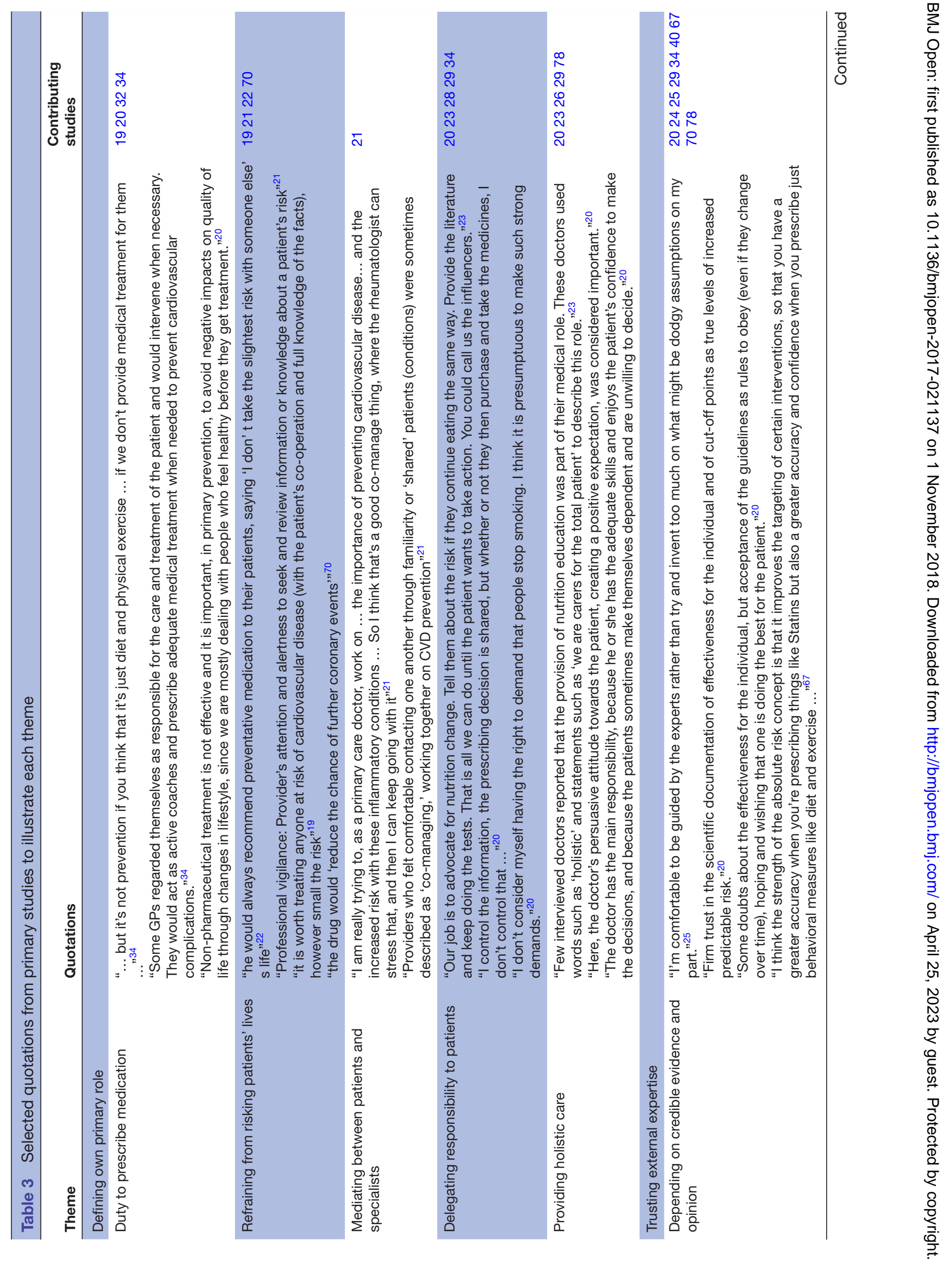




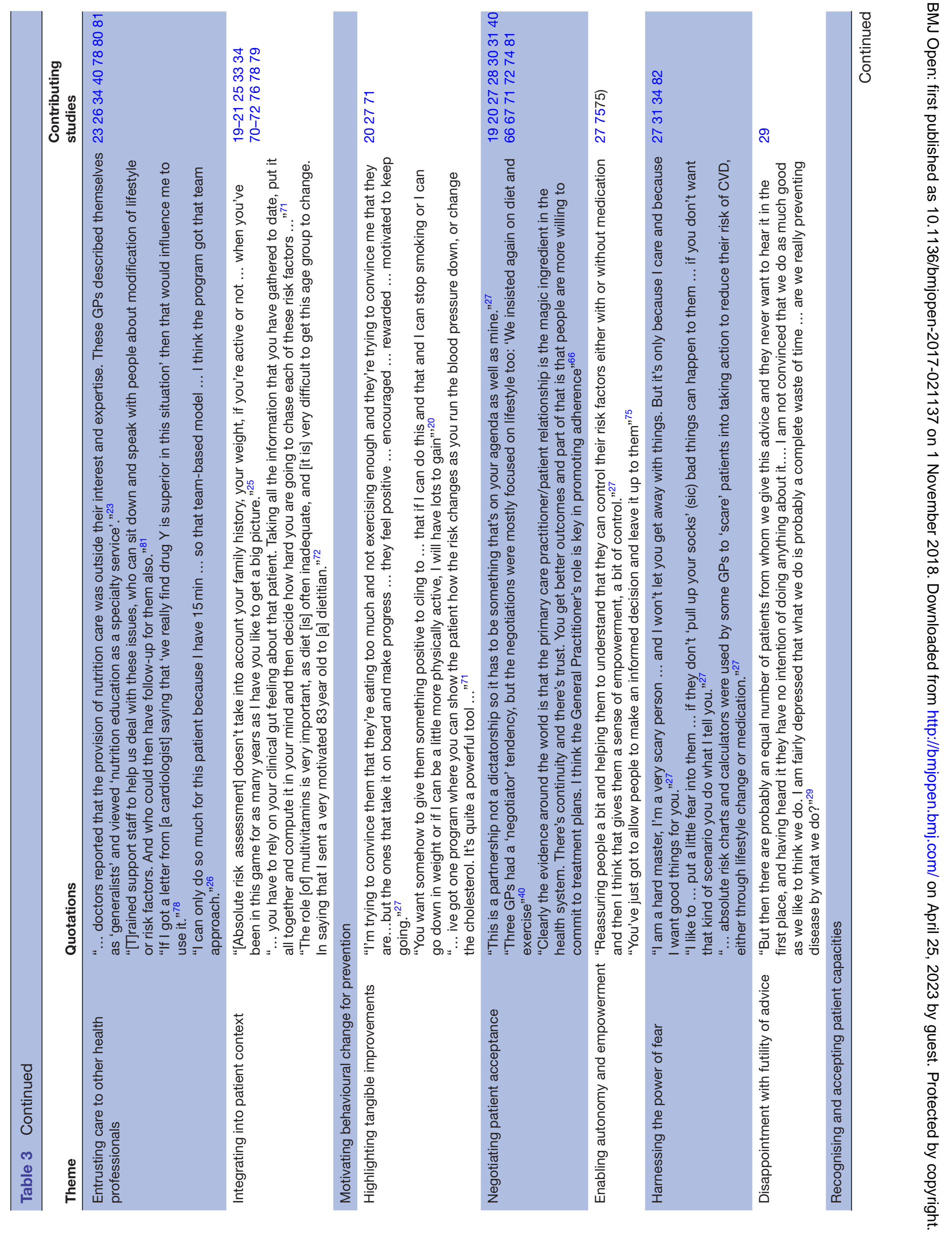




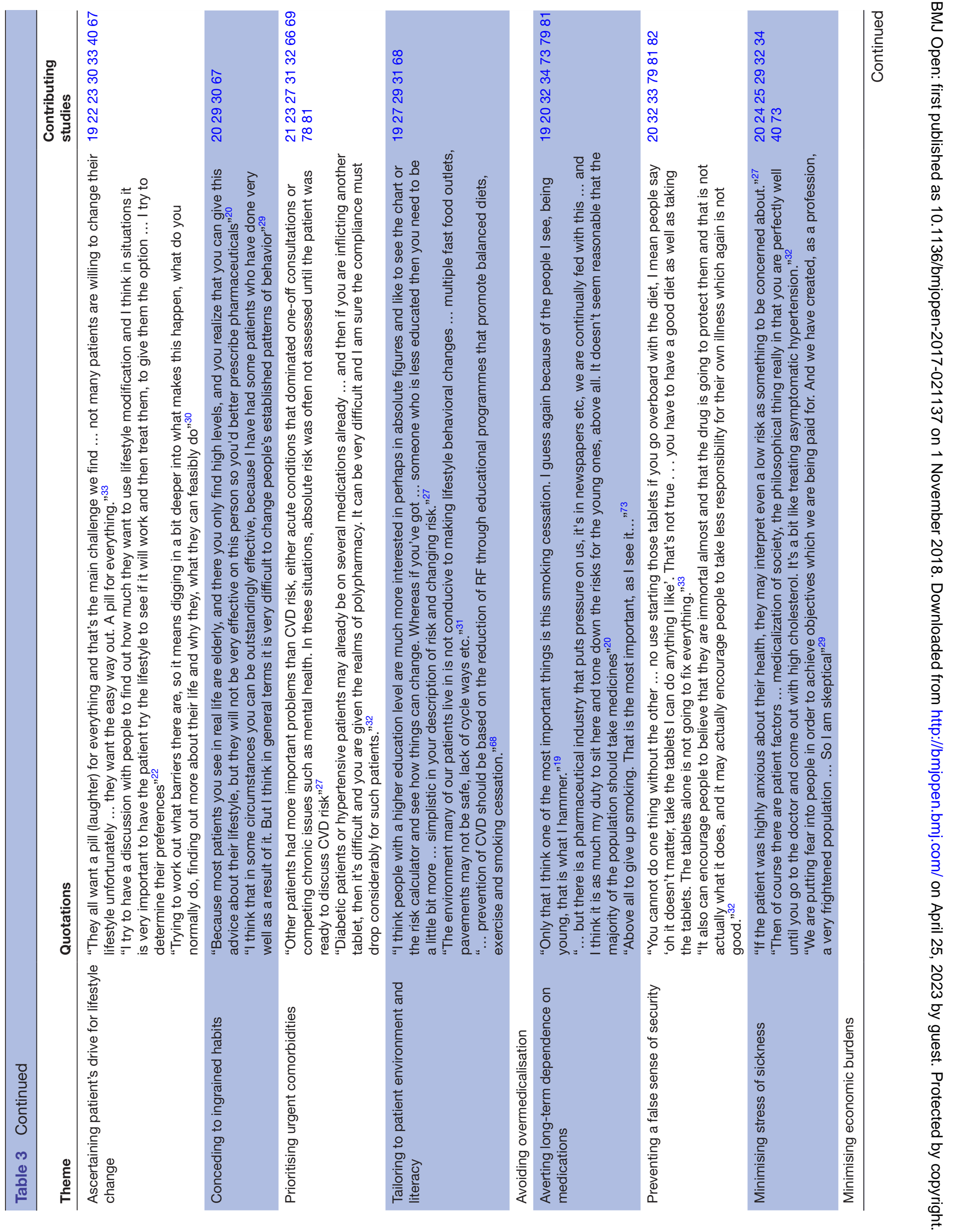


changes. Some GPs were enthusiastic about a team-based approach to prevention involving trained practice nurses and lifestyle advisors due to time constraints in their own consultations. ${ }^{26}$ For patients with comorbidities, some GPs considered specialists (eg, psychiatrists, cardiologists) to have more authority in educating their patients, as they had better knowledge of the patient's condition and medication.

\section{Integrating into patient context}

Some GPs considered the patient's family history and background when determining prevention strategies. They advocated the use of 'human judgement,' which incorporated 'emotional, political and logistical $^{19}$ considerations rather than accepting risk scores unconditionally. Others were unwilling to use risk scores to estimate pretreatment risk due to ambiguity of current guidelines regarding unique patient circumstances.

\section{Motivating behavioural change for prevention}

Highlighting tangible improvements

Some GPs used visual prompts to demonstrate to their patients the direct improvements in health and decrease of risk scores, which could be achieved through changes to lifestyle. They believed this approach encouraged patients to make active changes by giving them 'something positive to cling to'. ${ }^{27}$

\section{Negotiating patient acceptance}

When developing a strategy for preventing CVD, some GPs perceived that compromise was necessary in encouraging patients to cooperate. An explicit discussion and consideration of the patient's goals and priorities was seen to encourage patients to "work with the doctor, not against the doctor ${ }^{28}$ which built trust. Some GPs coproduced a strategy with the patient that was feasible for the patient's own situation.

\section{Enabling autonomy and empowerment}

Some GPs noted that patients with a lower risk of CVD were highly anxious about their risk factors and responded by giving patients reassurance and control over their medication and lifestyle prevention strategies. GPs perceived that patients who had a sense of autonomy and empowerment over their bodies felt more secure and willing to manage their risk factors.

\section{Harnessing the power of fear}

When managing patients at high risk of CVD, some GPs felt that scaring patients into action was necessary and warranted. They believed that an emphasis on the consequences of disregarding and being non-adherent to prevention strategies motivated patients to accept their advice, telling their patients 'if you don't want that kind of scenario you do what I tell you'.27 


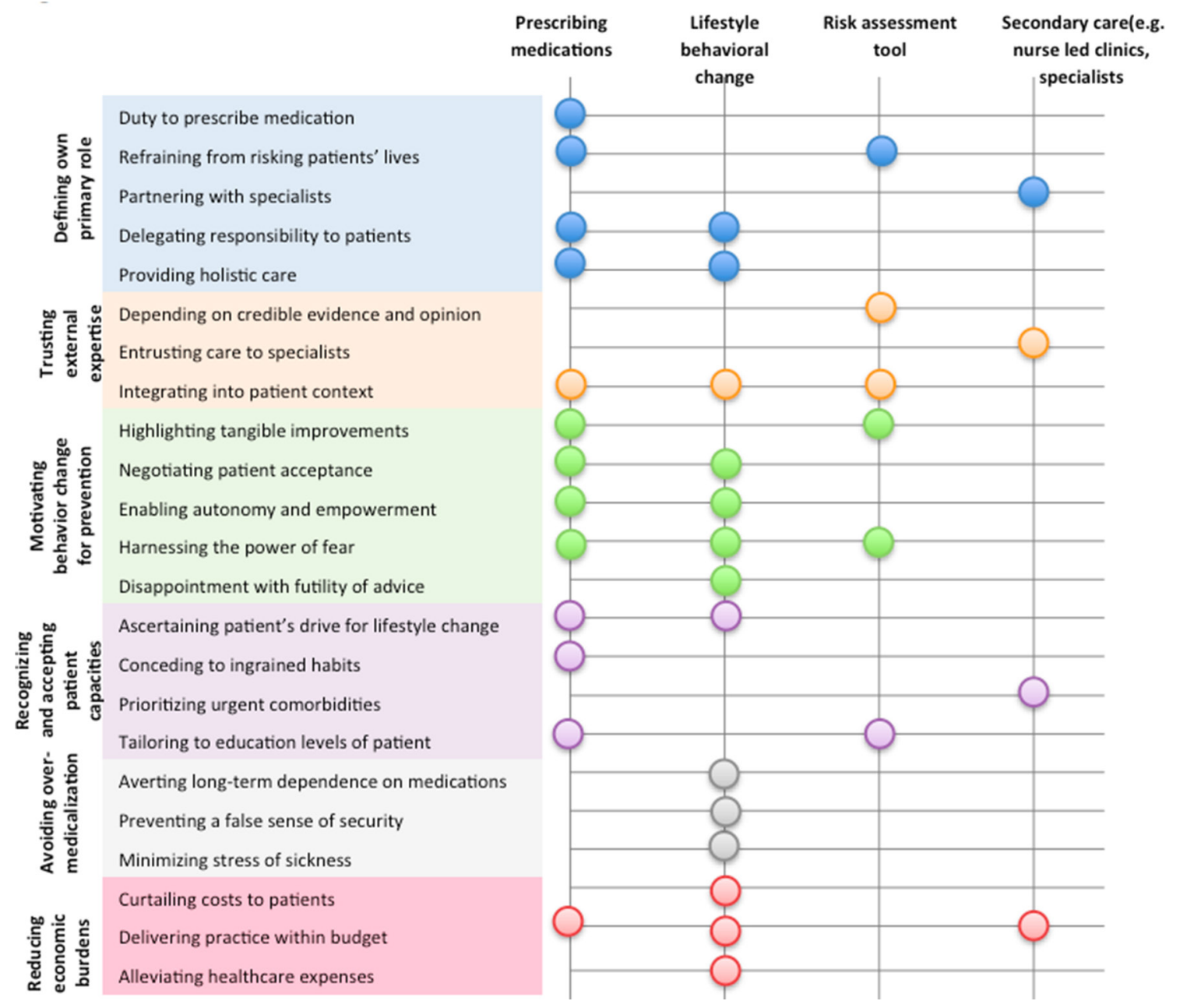

Figure 2 Matrix of prevention strategies and themes.

\section{Disappointment with futility of advice}

When patients were seen to lack motivation and had 'no intention of doing anything', some GPs perceived that their efforts to encourage the patient's uptake of prevention strategies were a 'waste of time'. In failing to motivate patients, GPs questioned their ability to prevent CVD in their patients, being '[un]convinced that we do as much good as we like to think we do'. ${ }^{29}$

\section{Recognising and accepting patient capacities \\ Ascertaining patients' drive for lifestyle change}

Some GPs felt they had to be realistic about their patients' desires to modify their daily lives, including changes to diet, physical activity and commencing a medication regimen. When patients seemed unwilling, GPs refrained from encouraging lifestyle changes or prescribing drugs to save their own time and resources.

\section{Conceding to ingrained habits}

Some GPs believed that patients who had established long-term lifestyle patterns in life (particularly patients who were obese and elderly) were unlikely to alter their habits (eg, smoking, diet), and so did not encourage lifestyle changes. They concluded that "medications are the only hope ${ }^{, 30}$ for patients who they believed were unable to adopt preventive behaviours.

\section{Prioritising urgent comorbidities}

In patients with comorbidities (eg, diabetes, mental illness), some GPs chose to delay prescribing strategies for CVD prevention to minimise the stress in patients of having to contend with multiple treatments. They focused on the patient's primary condition until they felt that the patient was emotionally and mentally prepared to discuss CVD prevention. For patients on medication for another disease, GPs were hesitant to prescribe more medication as they expected that the complexities of polypharmacy reduced overall adherence.

\section{Tailoring to patient environment and literacy}

Some GPs recognised that health literacy varied across the patient population and communicated the level of risk of CVD by using various approaches (eg, statistics, visual graphs, simpler words) according to the patient's educational attainment and socioeconomic status. GPs took into account the patient's environment to ensure feasibility of enacting prevention strategies, for example, '[the patient's neighborhood was not] 


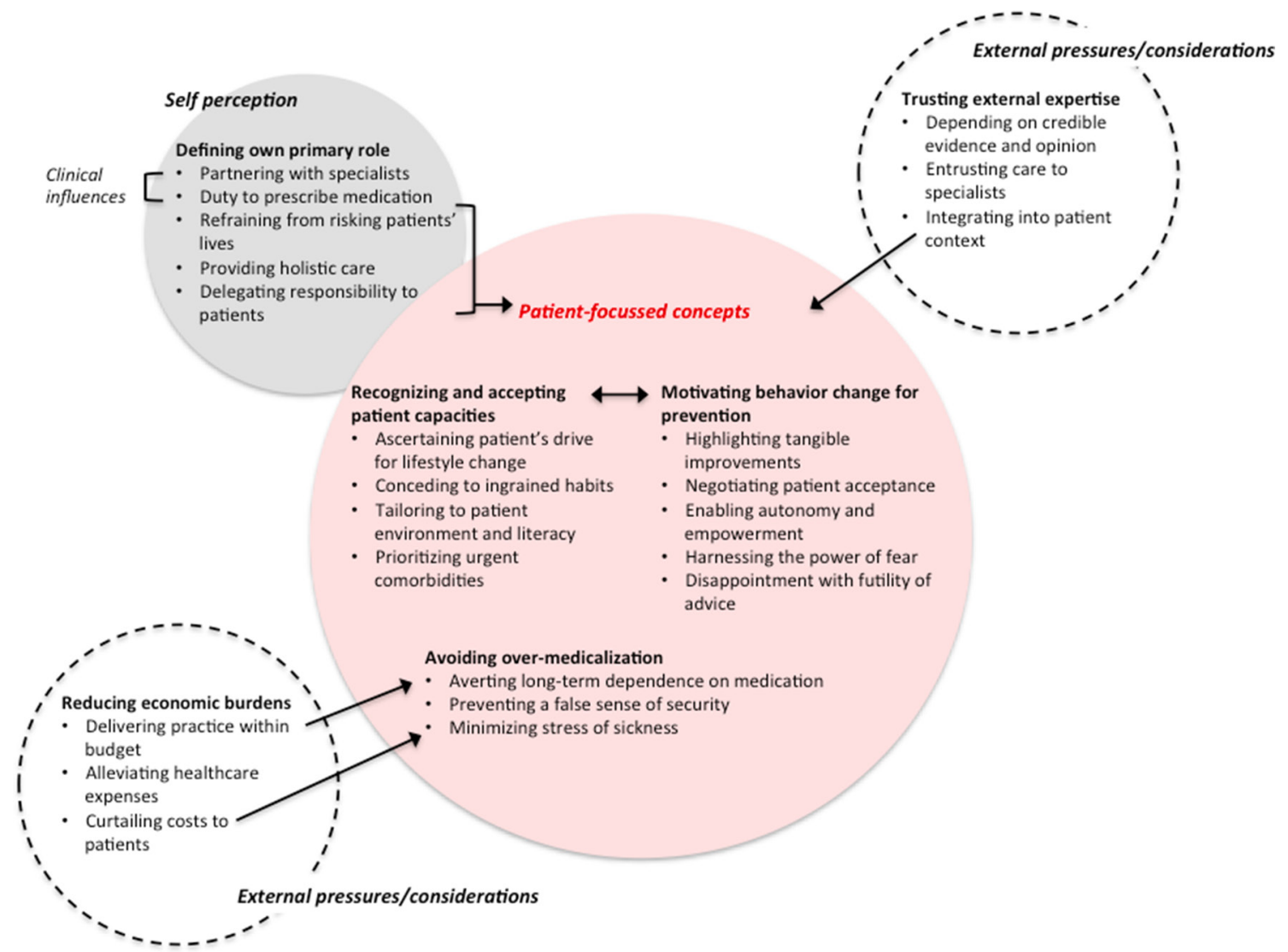

Figure 3 Thematic schema.

conductive to making lifestyle behavioural changes' with 'multiple fast food outlets'. ${ }^{31}$

\section{Avoiding overmedicalisation}

Averting long-term dependence on medications

Some GPs were concerned that most patients would be inclined to opt for medications as an immediate and easy solution, rather than make lifestyle changes. This was attributed to the marketing and widespread advertising of medications in the general public. They believed that giving young patients or patients who were not at high risk a lifetime prescription of medicine for preventive purposes should be avoided by encouraging lifestyle changes instead, to prevent a dependence on medications when it was not absolutely necessary.

\section{Preventing a false sense of security}

Some GPs were cautious and critical of 'medicaliz[ing] an unhealthy lifestyle ${ }^{20}$ as this encouraged patients to continue with their harmful habits (eg, sedentary lifestyle, poor diet, smoking) and 'forget about their lipid-lowering diet'. ${ }^{32}$ They noted that patients trusted the medicine to reduce their risk of CVD in spite of their lifestyle choices. With reference to medications and lifestyle modification, GPs believed that 'you cannot do one thing without the other ${ }^{33}$ and refrained from overprescribing medicine to prevent patients from believing that they were 'immortal'. ${ }^{32}$
Minimising stress of sickness

Regardless of the patient's level of risk for CVD, some GPs urged to avoid instilling unnecessary anxiety in patients, as 'fear becomes a major problem, ${ }^{29}$ and in turn elevates their risk further. They were hesitant to 'turn individuals into patients ${ }^{19}$ in the context of primary prevention for patients with low risk, as tests and preventive medications heightened their anxiety about their health. For example, a GP expected that a patient with high cholesterol would be conscious of their condition, and alerting them to their risk of heart attack would 'get themselves into more of a state'. ${ }^{27}$

\section{Minimising economic burdens}

Avoiding unjustified costs to patients

Some GPs especially in low socioeconomic regions like Guatemala were mindful of the economic burden of long-term medication on patients and thus prescribed medications only for patients at high risk as determined by their cholesterol or blood pressure. Some were also conscious and expressed concerns about the commercial interests of pharmaceutical companies-' $95 \%$ of treatment with statins is wasted' and 'fuelled by the interests of the pharmaceutical industry, ${ }^{22}$ However, others believed in the long-term cost-effectiveness of preventive medicine in minimising the potential for incurring costs for treatment of CVD. 


\section{Delivering practice within budget}

Some GPs in studies conducted in the UK and New Zealand were careful not to exceed their budget for drug prescriptions, and they were conscious of the limitations of funding available for their practice, which contended with external pressures (from pharmaceutical companies, health advertising) to offer drug treatment. GPs were more inclined to prescribe medicine for secondary prevention of CVD or for primary prevention in patients with a high risk of CVD to ensure an adequate budget for other patients in their practice.

\section{Alleviating healthcare expenses}

Some GPs perceived preventive procedures (blood tests, routine checks) to be a healthcare burden when the whole population was screened regardless of risk levels or immediate illnesses. This placed them under increasing pressure due to a greater demand for general screening. They were mindful of the resources and nurse time as well as their own time spent screening for risks for primary prevention in low-risk patients, as this detracted from resources available for patients who were 'actually ill'. ${ }^{29}$

\section{DISCUSSION}

Primary care healthcare providers believed that patients needed to be empowered to continue with medications and be motivated to make lifestyle changes for the prevention of CVD, but were challenged by the complexities of considering the patient's cognitive capacities, practical circumstances and health status. Some articulated a professional and ethical duty, to prescribe medications for the prevention of CVD and subsequently minimise the risk of future CVD events that could be preventable, and to avoid taking any responsibility for risking the patients' lives. However, some had concerns about prescribing patients long-term medications, particularly in the context of primary prevention and among patients who were not deemed to be at high risk of CVD.

Providers considered preventive strategies in the context of tensions between respecting patient autonomy and being too intrusive and paternalistic in recommending behavioural change. In making decisions about prescribing medication therapy, they considered the economic impact on their local practice (particularly in the UK) and broader healthcare costs, and specifically in terms of prioritising resources for patients with more urgent illnesses than to those who were asymptomatic with risk factors.

Differences in perspectives among GPs were apparent, in part reflecting their region of practice, sociodemographics of their patient population and the use of an absolute CVD or individual risk factor approach. In studies conducted in New Zealand, the UK and Guatemala, GPs deliberated on the financial burden of screening in the general population for primary prevention and costs of medications incurred to their patients as well as their own practice. Some GPs who practised in low socioeconomic areas believed that advising lifestyle changes, particularly in terms of diet, were futile as they believed that patients had limited access to healthy food in their local area. In earlier studies, GPs expressed more hesitation about prescribing medications, when this was not yet common practice nor widely recommended for primary prevention. ${ }^{20} 2534$ The majority of studies did not specify whether GPs used an absolute risk or individual risk factor approach to management, and did not detail the risk profile of their patients (ie, level of risk of CVD) when discussing preventive strategies. The concept of absolute risk was explicitly discussed in 17 (53\%) studies, and these studies were focused on GPs perspectives on tools for assessing absolute risk for CVD prevention.

Our study provides insights on the variability in decisions and approaches to CVD prevention among GPs. Approximately half of GPs use cardiovascular risk calculators and clinical guidelines, ${ }^{35}$ and those who do not use them have cited reasons including difficulties in using and interpreting the tools, and lack of applicability to their patient population in terms of age, socioeconomic background and family history. Our findings indicate that GPs may prefer to make their own judgement of individual risk factors acquired through experience rather than using absolute risk assessment tools.

While a vast majority of GPs would recommend drug prescription where appropriate, this does not necessarily translate into rates of actual prescription. For example, a study in the UK found that only $42 \%$ of patients eligible for lipid lowering drugs were prescribed them. ${ }^{12}{ }^{36}$ Our findings suggests that GPs' decisions to prescribe medication can be influenced by their perception of how likely the patient is willing to commence the regimen and how likely they are to adhere to medications. Also, some GPs expressed reluctance to 'medicalise' unhealthy lifestyles and foster a false sense of security in patients through medication.

A recent study found that more than half of GPs rated their ability to motivate behavioural change for CVD prevention as being 'not good', particularly for patients who were over 65 , male or obese. ${ }^{37}$ Our findings indicate that GPs believe that it may be difficult to motivate change in patients with established lifestyle habits, particularly in older or obese patients, and need a more immediate solution such as medication.

The themes identified in our synthesis reflect findings from studies of GPs' perspectives on the prevention of other chronic conditions such as diabetes. In a study on the prevention of type 2 diabetes,${ }^{38}$ GPs questioned their role and obligation in preventive care, where some expressed frustration at the societal pressure placed on them to screen patients for health risks despite the lack of funding and resources. They believed that education about healthy lifestyles should be delivered via schools and community programmes. Similarly, some GPs felt pressure from pharmaceutical companies to prescribe medication despite a limited budget for prescriptions within their own practice. ${ }^{29} 3940$ Instead, they preferred 
assistance from and delegation to specialists, nursing staff and dieticians. In the context of diabetes, GPs were also concerned that resources in general practice were increasingly directed towards management of diabetes, leading to the specialisation of staff (nurses, GPs) and a phasing out of general practice nurses. GPs similarly wanted to retain a generalist role in CVD prevention and provide comprehensive care involving all aspects of preventative health rather than a single focus on prevention of CVD. ${ }^{20}$

Our synthesis captured a broad range of the perspectives of GPs across different settings, and included attitudes pertaining to various CVD prevention strategies. However, there are some potential limitations. We were unable to differentiate whether GPs were using an absolute risk assessment or an individual risk factor approach, and whether perspectives were different in primary and secondary prevention, as these were not specified in most studies. Non-English articles were excluded, which could limit the transferability of the study's findings. We were unable to assess the prevalence of each theme. Systematic reviews of qualitative studies are designed to describe the range and depth of perspectives, and cannot quantify the prevalence of themes. However, table 3 include references of the studies that contributed to each theme.

Based on our findings, we suggest adapting or developing risk assessment tools that incorporate patient factors, motivating behavioural change in patients and ensuring adoption of cost-effective strategies in prescribing medications. In preventive care, treatment of individual risk factors may still be used over absolute risk assessment, with low uptake of risk assessment tools. ${ }^{7841}$ Greater use of absolute risk assessment tools and guidelines that explicitly address patient factors such as socioeconomic status, family history and lifestyle choices may be more useful for GPs. ${ }^{3942} 43$ Motivating adherence for both behavioural and pharmaceutical changes remains a challenge for GPs. Despite behavioural change being a highly cost-effective prevention strategy, ${ }^{44}{ }^{45}$ patient motivation and adherence to lifestyle advice is a barrier to preventive care. ${ }^{46-49} \mathrm{~A}$ multifaceted approach in a primary care setting involving supervised exercise sessions, follow-up calls and timed medication reminders in addition to current GP services can improve patients' adherence to prescribed medication and behavioural changes, while addressing barriers such as time and resource constraints for GPs. Recent lifestyle intervention trials in a primary care setting revealed reductions in individual risk factors (blood pressure, obesity, cholesterol), and improvements in total mortality as well as fatal and non-fatal cardiovascular events. ${ }^{50-55}$ Recent reviews of interventions revealed that most of those resulting in long-term patient adherence to behavioural changes included other healthcare professionals such as nurses, pharmacists and therapists, involving more convenient care (for individual patients), reinforcement of lifestyle advice, family and psychological therapy, telephone follow-up and technological supportive care (Fitbits, text messaging, apps). ${ }^{56-59}$
Our study also identified some research gaps, including perspectives on total (absolute) or individual (relative) risk assessment, effects of long-term dependence on medication, guidelines for prescription in primary care and the issues of gender and family support. When referring specifically to absolute CVD risk, some GPs discussed absolute risk assessment tools, but did not talk in depth about the concept of absolute risk and how they considered this in their decision-making and practice. A distinction between assessing absolute risk and individual risk factors is important in allowing for a more consistent and evidence-based evaluation for treatment plans. Current studies also did not address primary prevention in depth specifically, and some GPs expressed hesitation when providing primary preventive care to patients as they questioned the necessity for medication in asymptomatic patients and based on theoretical risk. Greater awareness of and adherence to evidence-based guidelines on medications for asymptomatic patients and risk factors may improve consistency of evaluating and managing CVD risk in patients. ${ }^{57}$ There was also a lack of data on GP's reflections on the role of family support. Family members can facilitate and support behavioural change by encouraging preventative lifestyle choices and reminding patients to take medications. ${ }^{6061}$ On the other hand, family members may dissuade patients from following a healthy lifestyle. ${ }^{6162}$ There was also limited data on gender. CVD has been considered a 'man's disease', as the prevalence of CVD is higher in men compared with women until the age of 75 years. ${ }^{6364}$ This has given rise to concerns about underestimating the risk of CVD in women, and it has been shown that weight loss programmes, for example, are recommended more frequently to men than women. ${ }^{6365}$ Women may not always present with typical chest pain in myocardial infarctions and coronary events, more commonly presenting with dyspnoea and fatigue. This makes early recognition and prevention of CVD more difficult in women. ${ }^{64}{ }^{65}$ Women can also present later than men and with more comorbidities, leading to misdiagnosis and poorer health outcomes ${ }^{65}$ Women are more likely to delay seeking treatment, attribute symptoms to non-cardiac causes and perceive pain levels differently to men. A combination of these factors can lead to delayed treatment and implementation of preventive measures. ${ }^{65}$

GPs believed that empowering patients to prevent CVD through adherence to lifestyle and medications was needed, but found it challenging to motivate behavioural change. Some considered that clinical decision-making for CVD prevention involved the patients' life stage and circumstances, capacity for self-management and their environment, which were not addressed in risk assessment and decision-making tools. Greater availability and adaptability of evidence-based strategies for assessing and managing CVD risk, including behavioural change in patients, may support decisions and implementation of CVD prevention activities among GPs. 
Author affiliations

${ }^{1}$ Sydney School of Public Health, The University of Sydney, Sydney, New South Wales, Australia

${ }^{2}$ Centre for Kidney Research, The Children's Hospital at Westmead, Westmead, New South Wales, Australia

${ }^{3}$ National Centre for Epidemiology and Population Health, Research School of Population Health, Australian National University, Canberra, Australian Capital Territory, Australia

${ }^{4}$ Sax Institute, Haymarket, New South Wales, Australia

${ }^{5}$ National Drug and Alcohol Research Centre, University of New South Wales, Sydney, New South Wales, Australia

${ }^{6}$ Academic Unit of General Practice, School of Medicine, Australian National University, Canberra, Australian Capital Territory, Australia

${ }^{7}$ Department of General Practice, Sydney Medical School Westmead, University of Sydney, Sydney, New South Wales, Australia

Acknowledgements We thank all participants for sharing their interesting thoughts and perspectives for this study.

Contributors IJ participated in the design of the search strategy, conducted the search, screened the studies, carried out thematic analysis and drafted the manuscript. AT designed the search strategy, participated in the thematic analysis and was the primary reviewer for the manuscript. EB, BC, AJ, JA, RJK, TU, KM, CSH, and JCC provided a critical review of the manuscript and provided final approval of the version to be published.

Funding The work was supported by a National Health and Medical Research Council of Australia Partnership Grant (1092674), including support from the National Heart Foundation of Australia. AT is supported by a NHMRC Fellowship (1106716).

Competing interests None declared.

Patient consent Not required.

Provenance and peer review Not commissioned; externally peer reviewed.

Data sharing statement № additional data are available.

Open access This is an open access article distributed in accordance with the Creative Commons Attribution Non Commercial (CC BY-NC 4.0) license, which permits others to distribute, remix, adapt, build upon this work non-commercially, and license their derivative works on different terms, provided the original work is properly cited, appropriate credit is given, any changes made indicated, and the use is non-commercial. See: http://creativecommons.org/licenses/by-nc/4.0/.

\section{REFERENCES}

1. O'Rourke K, VanderZanden A, Shepard D, et al. Cardiovascular Disease Worldwide, 1990-2013. JAMA 2015;314:1905.

2. WHO. Cardiovascular diseases (CVDs). 2016.

3. Deaton C, Froelicher ES, Wu LH, et al. The global burden of cardiovascular disease. Eur J Cardiovasc Nurs 2011;10:S5-13.

4. Ezzati M, Obermeyer Z, Tzoulaki I, et al. Contributions of risk factors and medical care to cardiovascular mortality trends. Nat Rev Cardiol 2015;12:508-30.

5. Volker N, Davey RC, Cochrane T, et al. Improving the prevention of cardiovascular disease in primary health care: the model for prevention study protocol. JMIR Res Protoc 2014;3:e33.

6. Harris M, Lloyd J. The role of Australian primary health care in the prevention of chronic disease ADMA. 2012.

7. Jansen J, Bonner C, McKinn S, et al. General practitioners' use of absolute risk versus individual risk factors in cardiovascular disease prevention: an experimental study. BMJ Open 2014;4:e004812.

8. Gupta R, Stocks NP, Broadbent J. Cardiovascular risk assessment in Australian general practice. Aust Fam Physician 2009;38:364-8.

9. Dallongeville J, Banegas JR, Halcox J, et al. Physicians' attitudes towards cardiovascular guidelines and risk assessment tools: Relation with the management of risk factors in the primary prevention setting. Eur Heart J 2011;32:973.

10. Bell A. 343 How Does the use of atrial fibrillation patient tools for stroke \& bleeding risk assessment (CHADS2/CHADSVASC/ HAS-BLED) in Canada Impact Prescribing Habits? Can J Cardiol 2012;28:S226.

11. Kones R. Rosuvastatin, inflammation, C-reactive protein, JUPITER and primary prevention of cardiovascular disease-a perspective. Drug Des Devel Ther 2010;4:383-413.
12. Wutzler A, Bannehr M, Pöhlmann AC, et al. The use of direct oral anticoagulants for stroke prevention in atrial fibrillation: a study on physicians' perspective and preferences. Int J Cardiol 2014:175:188-91.

13. Haigh KJ, Bingley J, Golledge J, et al. Barriers to screening and diagnosis of peripheral artery disease by general practitioners. Vasc Med 2013;18:325-30.

14. Jansen J, McKinn S, Bonner C, et al. General practitioners' decision making about primary prevention of cardiovascular disease in older adults: a qualitative study. PLoS One 2017;12:e0170228.

15. Tong A, Flemming K, Mclnnes E, et al. Enhancing transparency in reporting the synthesis of qualitative research: ENTREQ. BMC Med Res Methodol 2012;12:181.

16. Moher D, Liberati A, Tetzlaff J, et al. Preferred reporting items for systematic reviews and meta-analyses: the PRISMA statement. BMJ 2009;339:b2535

17. OECD. OECD Health Statistics 2016. Definitions, Sources and Methods. 2016.

18. Thomas J, Harden A. Methods for the thematic synthesis of qualitative research in systematic reviews. BMC Med Res Methodol 2008;8:45.

19. Greenfield S, Bryan S, Gill P, et al. Factors influencing clinicians' decisions to prescribe medication to prevent coronary heart disease. $J$ Clin Pharm Ther 2005;30:77-84.

20. Silwer L, Wahlström R, Lundborg CS. Views on primary prevention of cardiovascular disease-an interview study with Swedish GPs. BMC Fam Pract 2010;11:44.

21. Bartels CM, Roberts TJ, Hansen KE, et al. Rheumatologist and primary care management of cardiovascular disease risk in rheumatoid arthritis: patient and provider perspectives. Arthritis Care Res 2016;68:415-23.

22. Gale NK, Greenfield S, Gill P, et al. Patient and general practitioner attitudes to taking medication to prevent cardiovascular disease after receiving detailed information on risks and benefits of treatment: a qualitative study. BMC Fam Pract 2011;12:59.

23. Pomeroy SE, Worsley A. Nutrition care for adult cardiac patients: Australian general practitioners' perceptions of their roles. Fam Pract 2008;25:i123-9.

24. Fairhurst K, Huby G. From trial data to practical knowledge: qualitative study of how general practitioners have accessed and used evidence about statin drugs in their management of hypercholesterolaemia. BMJ 1998;317:1130-4.

25. Bonner C, Jansen J, McKinn S, et al. General practitioners' use of different cardiovascular risk assessment strategies: a qualitative study. Med J Aust 2013;199:485-9.

26. Volker N, Williams LT, Davey RC, et al. Implementation of cardiovascular disease prevention in primary health care: enhancing understanding using normalisation process theory. BMC Fam Pract 2017;18:28

27. Bonner C, Jansen J, McKinn S, et al. Communicating cardiovascular disease risk: an interview study of General Practitioners' use of absolute risk within tailored communication strategies. BMC Fam Pract 2014;15:106.

28. Wan Q, Harris MF, Zwar N, et al. Prerequisites for implementing cardiovascular absolute risk assessment in general practice: a qualitative study of Australian general practitioners' and patients views. J Eval Clin Pract 2010;16:no-4.

29. Williams SJ, Calnan M. Perspectives on prevention: the views of General Practitioners. Sociol Health IIIn 1994;16:372-93.

30. Speechly C, Bridges-Webb C, McKenzie S, et al. Patient and general practitioner attitudes to healthy lifestyle behaviours and medication following coronary heart disease: an exploratory study. Aust J Prim Health 2010;16:154-8.

31. Doolan-Noble F, Tracey J, Mann S. Why are there gaps in our management of those with high cardiovascular risk? J Prim Health Care 2012;4:21-9.

32. Kedward J, Dakin L. A qualitative study of barriers to the use of statins and the implementation of coronary heart disease prevention in primary care. Br J Gen Pract 2003;53:684-9.

33. Bonner C, Jansen J, McKinn S, et al. How do general practitioners and patients make decisions about cardiovascular disease risk? Health Psychol 2015;34:253-61.

34. Fhärm E, Rolandsson O, Johansson EE. 'Aiming for the stars'GPs' dilemmas in the prevention of cardiovascular disease in type 2 diabetes patients: focus group interviews. Fam Pract 2009;26:109-14.

35. Schmieder RE, Goebel M, Bramlage P. Barriers to cardiovascular risk prevention and management in Germany-an analysis of the EURIKA study. Vasc Health Risk Manag 2012;8:177-86.

36. Wu J, Zhu S, Yao GL, et al. Patient factors influencing the prescribing of lipid lowering drugs for primary prevention of cardiovascular 
disease in UK general practice: a national retrospective cohort study. PLoS One 2013;8:e67611.

37. Diehl K, Mayer M, Mayer F, et al. Physical activity counseling by primary care physicians: attitudes, knowledge, implementation, and perceived success. J Phys Act Health 2015;12:216-23.

38. Williams R, Rapport F, Elwyn G, et al. The prevention of type 2 diabetes: general practitioner and practice nurse opinions. $\mathrm{Br} J \mathrm{Gen}$ Pract 2004;54:531-5.

39. Goff DC, Lloyd-Jones D, Bennett G, et al. ACC/AHA guideline on the assessment of cardiovascular risk: A report of the American College of Cardiology/American Heart Association Task Force on Practice Guidelines. Circ 2013;129:S49-S73.

40. Lebeau JP, Cadwallader JS, Vaillant-Roussel H, et al. Genera practitioners' justifications for therapeutic inertia in cardiovascular prevention: an empirically grounded typology. BMJ Open 2016;6:e010639.

41. Chauhan U. Cardiovascular disease prevention in primary care. $\mathrm{Br}$ Med Bull 2007;81-82:65-79.

42. Anderson TJ, Grégoire J, Hegele RA, et al. 2012 update of the Canadian Cardiovascular Society guidelines for the diagnosis and treatment of dyslipidemia for the prevention of cardiovascular disease in the adult. Can J Cardiol 2013;29:151-67.

43. Piepoli M, Hoes A, Agewall S, et al. European Guidelines on cardiovascular disease prevention in clinical practice. Eur Heart $J$ 2016;2016:2315-81.

44. WHO. Obesity: preventing and managing the Global Epidemic. 1998.

45. Mills KT, Rubinstein A, Irazola V, et al. Comprehensive approach for hypertension control in low-income populations: rationale and study design for the hypertension control program in Argentina. Am J Med Sci 2014;348:139-45.

46. Barfoed BL, Paulsen MS, Christensen PM, et al. Associations between patients' adherence and GPs' attitudes towards risk, statin therapy and management of non-adherence-a survey and registerbased study. Fam Pract 2016;33:140-7.

47. Koelewijn-van Loon MS, van Steenkiste B, Ronda G, et al. Improving patient adherence to lifestyle advice (IMPALA): a cluster-randomised controlled trial on the implementation of a nurse-led intervention for cardiovascular risk management in primary care (protocol). BMC Health Serv Res 2008;8:9.

48. Sebate E, WHO. Adherence to long-term therapies. Evidence for action: WHO, 2003.

49. Hobbs FD, Erhardt L. Acceptance of guideline recommendations and perceived implementation of coronary heart disease prevention among primary care physicians in five European countries: the Reassessing European Attitudes about Cardiovascular Treatment (REACT) survey. Fam Pract 2002;19:596-604.

50. Ebrahim S, Taylor F, Ward K, et al. Multiple risk factor interventions for primary prevention of coronary heart disease. Cochrane Database Syst Rev 2011;1:CD001561.

51. Eriksson MK, Franks PW, Eliasson M. A 3-year randomized trial of lifestyle intervention for cardiovascular risk reduction in the primary care setting: the Swedish Björknäs study. PLoS One 2009;4:e5195.

52. Folta SC, Lichtenstein AH, Seguin RA, et al. The StrongWomenHealthy Hearts program: reducing cardiovascular disease risk factors in rural sedentary, overweight, and obese midlife and older women. Am J Public Health 2009;99:1271-7.

53. Wister A, Loewen N, Kennedy-Symonds $\mathrm{H}$, et al. One-year follow-up of a therapeutic lifestyle intervention targeting cardiovascular disease risk. CMAJ 2007;177:859-65.

54. Alliance NVDP. Guidelines for the management of absolute cardiovascular risk, 2012.

55. Murphy E, Vellinga A, Byrne M, et al. Primary care organisational interventions for secondary prevention of ischaemic heart disease: a systematic review and meta-analysis. $\mathrm{Br} J$ Gen Pract 2015;65:e460-8.

56. Haynes RB, Ackloo E, Sahota N, et al. Interventions for enhancing medication adherence. Cochrane Database Syst Rev 2008;53. CD000011.

57. Glynn LG, Murphy AW, Smith SM, et al. Interventions used to improve control of blood pressure in patients with hypertension. Cochrane Database Syst Rev 2010;7. CD005182.

58. Ogedegbe G, Schoenthaler A. A systematic review of the effects of home blood pressure monitoring on medication adherence. $J$ Clin Hypertens 2006;8:174-80.
59. Khan N, Marvel FA, Wang J, et al. Digital health technologies to promote lifestyle change and adherence. Curr Treat Options Cardiovasc Med 2017;19:60.

60. Cole JA, Smith SM, Hart N, et al. Do practitioners and friends support patients with coronary heart disease in lifestyle change? a qualitative study. BMC Fam Pract 2013;14:126.

61. Falba TA, Sindelar JL. Spousal concordance in health behavior change. Health Serv Res 2008;43:96-116.

62. Rosland AM, Heisler M, Piette JD. The impact of family behaviors and communication patterns on chronic illness outcomes: a systematic review. J Behav Med 2012;35:221-39.

63. Mosca L, Barrett-Connor E, Wenger NK. Sex/gender differences in cardiovascular disease prevention: what a difference a decade makes. Circulation 2011;124:2145-54.

64. Chesler RM, Ho DW, Ramkissoon K. Women and cardiovascular disease: gender-based issues regarding detection and primary prevention. Health 2014;6:2790-801.

65. Finks SW, Spencer A, Hume A. Cardiovascular disease in women. Pharm Self Assessment Program. 2010;1:179-99.

66. Liu H, Massi L, Laba TL, et al. Patients' and providers' perspectives of a polypill strategy to improve cardiovascular prevention in Australian primary health care: a qualitative study set within a pragmatic randomized, controlled trial. Circ Cardiovasc Qual Outcomes 2015;8:301-8.

67. Wan $Q$, Harris MF, Zwar N, et al. Sharing risk management: an implementation model for cardiovascular absolute risk assessment and management in Australian general practice. Int $\mathrm{J}$ Clin Pract 2008:62:905-11.

68. Montano CM, Estrada K, Chávez A, et al. Perceptions, knowledge and beliefs about prevention of cardiovascular diseases in Villa Nueva, Guatemala. Prev Control 2008;3:1-9.

69. Nielen MM, Assendelft WJ, Drenthen AJ, et al. Primary prevention of cardio-metabolic diseases in general practice: a Dutch survey of attitudes and working methods of general practitioners. Eur $J$ Gen Pract 2010;16:139-42.

70. Sapre N, Mann S, Elley CR. Doctors' perceptions of the prognostic benefit of statins in patients who have had myocardial infarction. Intern Med J 2009;39:277-82.

71. Torley D, Zwar N, Comino EJ, et al. GPs' views of absolute cardiovascular risk and its role in primary prevention. Aust Fam Physician 2005;34:503.

72. Weiner M, Wells S, Kerse N. Perspectives of general practitioners towards evaluation and treatment of cardiovascular diseases among older people. J Prim Health Care 2009;1:198-206.

73. Wahlström R, Dahlgren LO, Tomson G, et al. Perspectives on prevention: the views of General Practitioners. Adv Health Sci Educ 1997;2:221-36

74. Fisseni G, Lewis DK, Abholz HH. Understanding the concept of medical risk reduction: a comparison between the UK and Germany. Eur J Gen Pract 2008;14:109-16.

75. Lewis DK, Robinson J, Wilkinson E. Factors involved in deciding to start preventive treatment: qualitative study of clinicians' and lay people's attitudes. BMJ 2003;327:841.

76. Liew SM, Blacklock C, Hislop J, et al. Cardiovascular risk scores: qualitative study of how primary care practitioners understand and use them. Br J Gen Pract 2013;63:e401-7.

77. Macintosh MJ, Lacey EA, Tod AM. Secondary prevention for coronary heart disease: a qualitative study. Br J Nurs 2003;12:462-9.

78. Summerskill WS, Pope C. 'I saw the panic rise in her eyes, and evidence-based medicine went out of the door.' An exploratory qualitative study of the barriers to secondary prevention in the management of coronary heart disease. Fam Pract 2002;19:605-10.

79. Virdee SK, Greenfield SM, Fletcher K, et al. Would primary healthcare professionals prescribe a polypill to manage cardiovascular risk? A qualitative interview study. BMJ Open 2013;3:e002498.

80. Wright CA, Osborn DP, Nazareth I, et al. Prevention of coronary heart disease in people with severe mental illnesses: a qualitative study of patient and professionals' preferences for care. BMC Psychiatry 2006;6:16.

81. Rosal MC, Ockene JK, Luckmann R, et al. Coronary heart disease multiple risk factor reduction. Providers' perspectives. Am J Prev Med 2004:27:54-60.

82. Tanner RM, Safford MM, Monda KL, et al. Primary care physician perspectives on barriers to statin treatment. Cardiovasc Drugs Ther 2017;31:303-9. 